\title{
Identifikasi Jenis dan Mutu Teh Menggunakan Pengolahan Citra Digital dengan METODE JARINGAN SYARAF TIRUAN
}

Identification Type and Quality of Tea Using Digital Image Processing By Artificial Neural Network Method

\author{
Mas'ud Effendi' ${ }^{1)}$, Fitriyah'1), Usman Effendi ${ }^{1)}$ \\ 1)Jurusan Teknologi Industri Pertanian, Fakultas Teknologi Pertanian, Universitas Brawijaya \\ Jl. Veteran-Malang 65145 \\ Email Penulis: mas.ud@ub.ac.id
}

\begin{abstract}
ABSTRAK
Teh merupakan hasil pucuk daun muda tanaman Camelia sinensis dan menjadi salah satu produk ekspor terbesar. Salah satu kendala yang dihadapi konsumen dalam memilih teh berkualitas baik adalah minimnya pengetahuan konsumen terhadap jenis dan mutu teh, sehingga menyebabkan perbedaan penentuan jenis dan mutu teh. Penelitian untuk mengidentifikasi jenis dan mutu teh dari 3 jenis teh yaitu teh hitam, teh hijau, dan teh putih perlu dilakukan. Tujuan penelitian ini adalah merancang aplikasi sistem pengolahan citra digital untuk mengidentifikasi jenis dan mutu teh serta menentukan hasil pengenalan terbaik berdasarkan akurasi yang diperoleh. Penelitian ini menerapkan metode pengolahan citra digital dengan teknik Learning Vector Quantization yang menggunakan 6 parameter warna yaitu R, G, B, H, S, dan I sebagai neuron input dan 13 mutu dari 3 jenis teh sebagai neuron output. Penelitian menggunakan 403 citra dengan perbandingan training dan testing sebesar 80:20. Akurasi training diperoleh sebesar 62,7\%. Prediksi menggunakan 26 sampel citra teh berbeda menunjukkan tingkat akurasi sebesar $42,31 \%$.
\end{abstract}

Kata Kunci: jaringan syaraf tiruan, learning vector quantization (LVQ), teh

\begin{abstract}
Tea is the result of young leaf shoots Camelia sinensis plant and become one of the largest export products. One of the constraints faced by consumers in choosing good quality tea is the lack of consumer knowledge of the type and quality of tea, thus causing differences in the determination of the type and quality of tea. Research to identify the type and quality of tea from 3 types of tea that is black tea, green tea, and white tea needs to be done. The purpose of this study is to design the application of digital image processing system to identify the type and quality of tea and determine the best recognition result based on the accuracy obtained. This research applies method of digital image processing with Learning Vector Quantization which use 6 color parameter that is $R, G$, $B, H, S$, and I as input neuron and 13 quality from 3 tea type as output neuron. The study used 403 images with a comparison of training and testing of 80:20. Training accuracy obtained was $62.7 \%$. Prediction using 26 samples of different tea images showed an accuracy of $42.31 \%$.
\end{abstract}

Keywords: artificial neural network, learning vector quantization (LVQ), tea

Diterima : 29 Maret 2017 ; Disetujui : 18 Juli 2017; Online Published : 26 Oktober 2017

DOI : 10.24198/jt.vol11n2.7

Identifikasi Jenis dan Mutu Teh Menggunakan Pengolahan Citra Digital dengan Metode Jaringan Syaraf 


\section{PENDAHULUAN}

Salah satu komoditas ekspor yang menyumbang besar bagi devisa negara adalah teh (Dirjen Perkebunan, 2014). Komoditas teh dihasilkan dari pucuk daun tanaman teh Camellia sinensis melalui proses pengolahan tertentu. Berdasarkan proses pengolahannya, ada tiga jenis teh yaitu teh hijau, teh hitam, dan teh oolong (Khan, 2007 dalam Jun Xi, 2013). Teh putih juga termasuk ke dalam jenis teh yang dibedakan berdasarkan proses pengolahannya. Teh putih ditentukan dari hasil pengeringan pucuk teh yang kemudian menjadi jenis mutu silver needle (Rohdiana, 2015). Selain itu, teh bisa dibedakan dari kandungan flavonol dan antosianin Mandel et al. (2005) serta kandungan total polifenol (Yashin et al., 2015).

Teh merupakan salah satu produk olahan hasil perkebunan yang banyak dikonsumsi masyarakat dalam kehidupan sehari-hari. Salah satu kendala yang sering dihadapi adalah menentukan kualitas mutu teh dikarenakan minimnya pengetahuan produsen dan konsumen terhadap jenis dan mutu teh. Cara mengidentifikasi mutu teh yang dilakukan masih banyak menggunakan cara manual dengan mengamati secara langsung teh. Kelemahan identifikasi secara manual sangat dipengaruhi oleh subjektifitas sehingga hasil identifikasi yang diperoleh tidak konsisten. Oleh karena itu diperlukan adanya metode yang memudahkan produsen maupun konsumen dalam memilih kualitas teh yang baik secara cepat. Aplikasi tersebut dapat dibuat dengan pengolahan citra digital dan jaringan syaraf tiruan. Kombinasi metode tersebut telah banyak digunakan masyarakat untuk dapat membedakan beberapa komoditas yang sulit diidentifikasi secara langsung, seperti identifikasi tingkat kematangan buah (Warman dkk, 2015) dan kualitas biji-bijian (Adrizal dkk, 2011). Penelitian ini dimaksudkan sebagai usaha untuk mengurangi tingkat kesalahan identifikasi mata manusia akibat ketidaktahuan atau kurangnya pengetahuan masyarakat tentang teh. Pemanfaatan teknologi pengolahan citra digital diharapkan dapat tercipta aplikasi yang lebih memudahkan masyarakat dalam menentukan jenis dan mutu teh dalam waktu yang singkat dan biaya murah, terlebih bagi produsen.

Pengolahan citra digital adalah teknik mengolah citra yang bertujuan memperbaiki kualitas citra agar mudah diinterpretasi oleh manusia atau mesin komputer yang dapat berupa foto maupun gambar bergerak (Sutoyo dkk., 2009). Pengolahan citra digital memiliki beberapa kelebihan, yaitu murah, cepat, dan tidak merusak sampai yang diukur dan mampu mengidentifikasi fisik produk secara obyektif (Somantri, 2010). Jaringan Syaraf Tiruan (JST) merupakan sebuah model yang mengadopsi cara kerja neuron dengan fokus pada cara kerja syaraf otak (Luthfi dan Kusrini, 2009). Jaringan Syaraf Tiruan dapat menyelesaikan masalahmasalah yang kompleks dan sulit dipahami. Salah satu teknik jaringan syaraf tiruan yaitu Learning Vector Quantization (LVQ). Teknik LVQ bertujuan untuk melakukan visualisasi data dengan cara melakukan pengelompokan (cluster) menggunakan vector quantization. Kelebihan yang dihasilkan teknik ini dapat memberikan waktu yang relatif singkat dibandingkan teknik JST yang lain (Azmi, 2014).

\section{METODOLOGI PENELITIAN}

Penelitian ini dilakukan di Pusat Penelitian Teh dan Kina (PPTK) Bandung, Jawa Barat dengan mengambil sampel teh hitam, teh hijau, dan teh putih. Pengolahan data 
penelitian dilakukan di Laboratorium Komputasi dan Analisis Sistem, Jurusan Teknologi Industri Pertanian, Fakultas Teknologi Pertanian, Universitas Brawijaya, Malang. Tahapan penelitian sistem pengolahan citra digital teh dibuat melalui akuisisi citra, preprocessing, ekstraksi fitur, training, testing dan prediksi.

Analisis perancangan sistem dilakukan untuk membahas secara keseluruhan tentang proses lebih lanjut data dalam sistem yang dibuat. Data yang diproses lebih lanjut adalah sampel citra yang diambil dari masing-masing jenis dan mutu teh hitam orthodox, teh hijau dan teh putih. Setiap sampel diambil citranya diperlukan 2 gram teh. Kebutuhan sampel sebanyak 2 gram tersebut pada dasarnya tidak ada acuan tertentu dalam proses pengambilan citra. Pengambilan citra hanya difokuskan pada jarak fokus terhadap objek teh. Pengambilan citra dilakukan menggunakan scanner Canon Lide 90 yang langsung terhubung dengan komputer. Scanner yang digunakan mudah didapat dan tersedia secara komersial (Adnan dkk, 2013). Resolusi per citra yang diambil dan besar pikselnya sama. Citra yang diambil dilakukan dengan pencahayaan langsung dari scanner. Sampel citra yang diambil secara keseluruhan sebanyak 403 citra sebagai data training dan data testing. Penggunaan jumlah data training dan testing dilakukan dengan membandingkan data sebesar 60:40, 70:30 dan $80: 20$. Perbandingan data yang dilakukan bertujuan untuk mendapatkan tingkat akurasi yang lebih tinggi.

Pembuatan sistem dilakukan dengan menggunakan software dengan bantuan komputer untuk dapat membedakan antara jenis dan mutu teh dengan menggunakan metode jaringan syaraf tiruan dengan algoritma Learning Vector Quantization (LVQ). Algoritma pelatihan LVQ bertujuan untuk menghasilkan vektor referensi yang sangat diskriminatif melalui pembelajaran (Degang et al., 2007). Algoritma LVQ yang akan diterapkan untuk membedakan mutu teh berdasarkan ciri fisiknya yaitu warna partikel. Untuk mengetahui jenis dan mutu warna partikel teh dapat dilihat pada SNI 01-3836-2000. Tahap analisis sistem dibagi menjadi dua proses, yaitu proses pengolahan citra digital dan pengenalan citra teh dengan menggunakan jaringan syaraf tiruan.

\section{HASIL DAN PEMBAHASAN}

\section{Analisis Perancangan dan Implementasi Sistem}

Tahap analisis perancangan dan implementasi sistem dimulai dari pengambilan citra teh dengan menggunakan scanner yang terhubung langsung dengan laptop. Cara mengambil citra menggunakan scanner adalah meletakkan sampel di atas kaca scanner, kemudian sampel ditutup dengan penutup scanner untuk memfokuskan cahaya agar citra tidak dipengaruhi oleh sumber cahaya lain. llustrasi pengambilan citra dapat dilihat pada Gambar 1. Berkas citra yang diambil disimpan dalam format .jpg, dikarenakan format ini mampu menyimpan data gambar dengan tingkat gradasi warna yang tinggi.

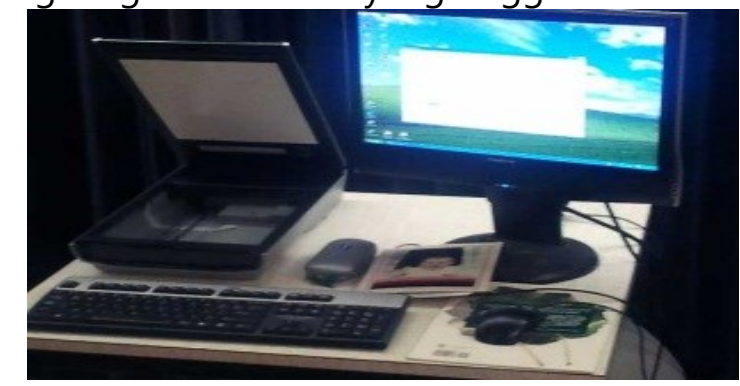

Gambar 1. Ilustrasi pengambilan citra

\section{Tahap Akuisisi Citra}

Tahap akuisisi citra dilakukan untuk menyeragamkan ukuran piksel pada citra yang diambil melalui scanner. Penggunaan scanner bertujuan untuk agar teknik tersebut bisa direplikasi dengan harga relatif murah dan tidak banyak membutuhkan persyaratan teknis. 
Dalam menyeragamkan ukuran piksel, dilakukan cropping citra dengan ukuran $300 \times 300$ piksel, kemudian di resize. Citra teh yang di-cropping dan resize dapat dilihat pada Gambar 2.

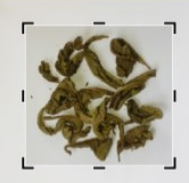

(a) Citra di-crop

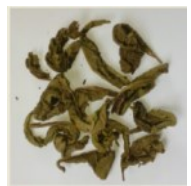

(b) Citra resize
Gambar 2. Citra teh cropping dan resize

\section{Tahap Preprocessing dan Ekstraksi Fitur}

Tahap preprocessing merupakan tahap dimana citra yang dilakukan ekstraksi fitur diubah terlebih dahulu menjadi citra grayscale atau citra biner. Pada tahapan ini, citra yang menjadi objek ekstraksi diubah menjadi warna putih, sebaliknya latar belakang objek diubah menjadi warna hitam. Tampilan interface preprocessing dan ekstraksi fitur dapat dilihat pada Gambar 3. Adapun ekstraksi fitur yang digunakan yaitu menghitung nilai warna Red, Green, Blue, Hue, Saturation, Intensity seperti yang terlihat pada Gambar 3. Pengukuran nilai rata-rata $R G B$ dan indeks rata-rata $R G B$ didapat sebaran nilai rata-rata $R G B$ dan indeks $R G B$ rata-rata minimum dan maksimum untuk tiap teh. Selanjutnya dibuat sebaran nilai rata-rata RGB dan indeks rata-rata RGB teh untuk masing-masing jenis dan mutu (Hendrawan dan Sumardi, 2005).

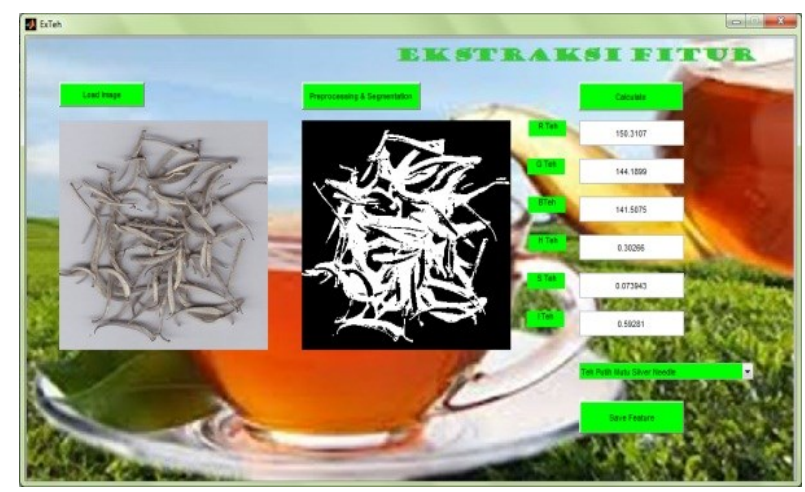

Gambar 3. Tampilan interface preprocessing dan ekstraksi fitur

\section{Tahap Training dan Testing}

Proses training dilakukan untuk melatih jaringan syaraf tiruan agar mampu mengidentifikasi perbedaan antar jenis teh dengan membentuk arsitektur jaringan dan menetapkan nilai bobot untuk tahap pengenalan. Arsitektur jaringan yang diperoleh ditentukan oleh jumlah data training yang digunakan dan variabel training yang dapat ditentukan oleh user sesuai dengan kebutuhan. Variabel training yang digunakan meliputi hidden neuron, learning rate, epoch dan error goal. Arsitektur jaringan yang diperoleh digunakan pada tahap testing. Proses testing data merupakan tahap pengujian sistem yang telah dibuat. Tampilan interface training dan testing dapat dilihat pada Gambar 4.

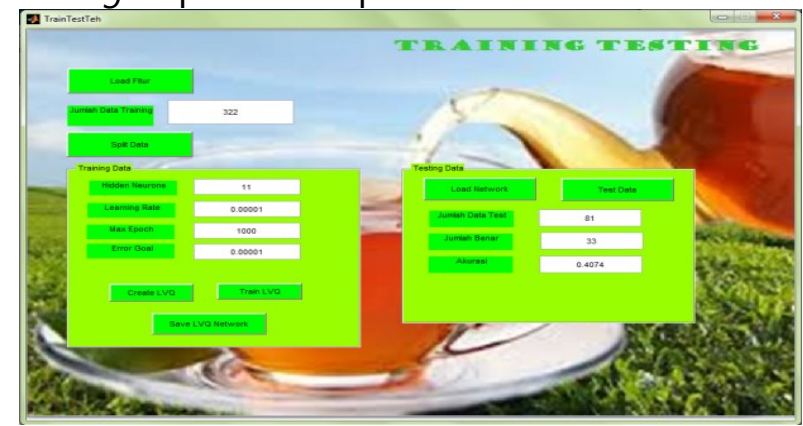

Gambar 4. Tampilan interface training dan testing

Penentuan hidden neuron didasarkan pada jumlah neuron input layer dan neuron output layer. Jumlah neuron hidden layer harus berada diantara ukuran neuron input layer dan neuron output layer (Heaton, 2008). Menurut Adha (2013), penggunaan learning rate memberikan pengaruh waktu terhadap tercapainya target yang diinginkan. Setiap iterasi dilakukan perhitungan jarak untuk mendapatkan jarak kelas terdekat dari vektor masukan terhadap kelas keluaran. Jika jarak kelas terdekat yang didapatkan sama dengan 
target, maka dilakukan penambahan bobot dari nilai sebelumnya. Tetapi jika tidak, maka nilai bobot dikurangi dari nilai bobot sebelumnya. Proses training menghasilkan nilai bobot yang digunakan dalam proses testing. Hasil akurasi proses training secara keseluruhan yaitu $62,7 \%$ yang dapat dilihat pada Gambar 5.

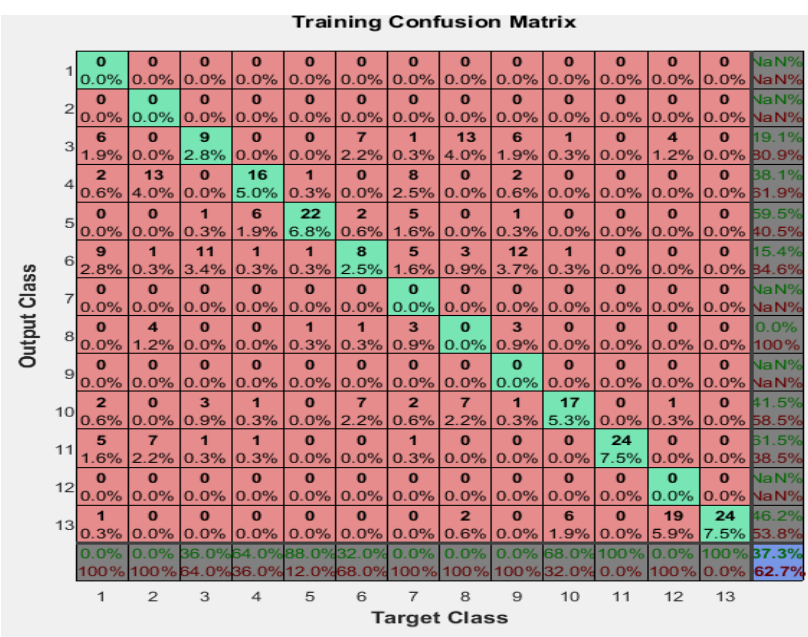

Gambar 5. Hasil akurasi proses training

Proses testing tidak beda jauh dengan proses training, yaitu mencari jarak terdekat dari vektor input terhadap kelas output. Proses testing tidak melakukan iterasi ketika mencari jarak terdekat. Jika jarak dari kelas terdekat telah diperoleh, maka kelas ini yang dikembalikan sebagai hasil proses testing. Pada penelitian ini, akurasi testing yang didapatkan yaitu $40,74 \%$. Akurasi yang didapatkan dalam penelitian ini masih rendah disebabkan beberapa faktor seperti noise, karena masih terdapat kotoran/debu pada kaca scanner.

\section{Tahap Prediksi}

Tahap prediksi merupakan proses identifikasi untuk mengetahui hasil jenis dan mutu teh dari citra yang telah diinputkan. Pada tahap prediksi ini dilakukan pengenalan citra diluar data citra yang digunakan pada saat proses training dan testing. Tampilan interface prediksi dapat dilihat pada Gambar 6 .

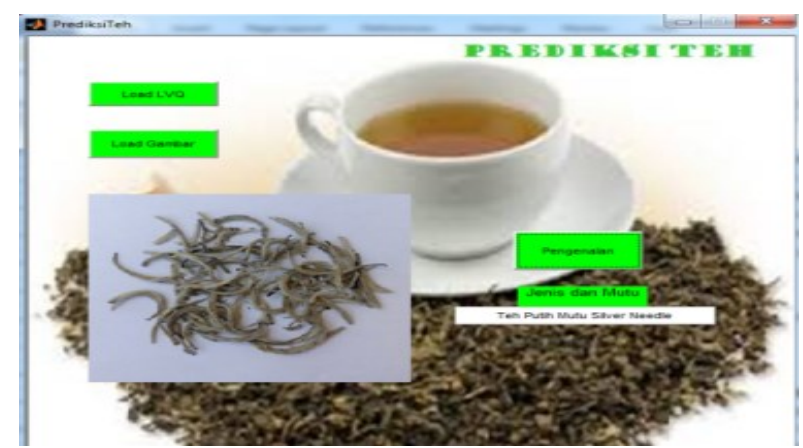

Gambar 6. Tampilan interface prediksi

\section{Analisis Hasil Training dan Testing}

Pada tahap training terdapat variabel training yang dapat diubah sesuai kebutuhan user. Variabel training pada proses training meliputi hidden neuron, learning rate, epoch, dan error goal. Variabel training tersebut mempengaruhi hasil dari akurasi sistemnya. Jika hasil akurasi sistem tinggi, maka memberikan hasil prediksi yang lebih baik pada proses pengenalan citra. Semakin banyak variasi variabel bebas yang digunakan, user dapat memperoleh akurasi sistem yang dikehendaki. Dalam hal ini, variasi variabel training yang digunakan adalah hidden neuron dan learning rate terhadap perbandingan jumlah data yang digunakan.

\section{Variasi Hidden Neuron}

Pada variasi hidden neuron, hidden neuron yang digunakan yaitu 6, 9, 11, dan 13 . Variasi hidden neuron ini mempengaruhi tingkat akurasi sistem. Hasil variasi hidden neuron pada tahap training dan testing dengan menggunakan perbandingan jumlah data 60:40 dapat dilihat pada Tabel 1, sedangkan hasil variasi hidden neuron dengan perbandingan jumlah data 70:30 dan 80:20 dapat dilihat pada Tabel $\mathbf{2}$ dan Tabel 3. 
Tabel 1. Variasi hidden neuron dengan perbandingan data $60: 40$

\begin{tabular}{|c|c|c|c|c|}
\hline \multirow{2}{*}{$\begin{array}{l}\text { Variabel } \\
\text { Hidden }\end{array}$} & \multicolumn{4}{|c|}{ Variasi Hidden Neuron } \\
\hline & 6 & 9 & 11 & 13 \\
\hline Neuron & & & & \\
\hline $\begin{array}{l}\text { Learning } \\
\text { Rate }\end{array}$ & 0,00001 & 0,00001 & 0,00001 & 0,00001 \\
\hline Epoch & 1000 & 1000 & 1000 & 1000 \\
\hline Error & 0,00001 & 0,00001 & 0,00001 & 0,00001 \\
\hline $\begin{array}{l}\text { Jumlah } \\
\text { Training }\end{array}$ & 242 & 242 & 242 & 242 \\
\hline $\begin{array}{l}\text { Jumlah } \\
\text { Testing }\end{array}$ & 161 & 161 & 161 & 161 \\
\hline $\begin{array}{l}\text { Jumlah } \\
\text { Benar }\end{array}$ & 26 & 22 & 31 & 36 \\
\hline Akurasi & $16,15 \%$ & $13,66 \%$ & $19,25 \%$ & $22,36 \%$ \\
\hline
\end{tabular}

Tabel 2. Variasi hidden neuron dengan perbandingan data 70:30

\begin{tabular}{lcccc}
\hline \multicolumn{1}{c}{ Variabel } & \multicolumn{4}{c}{ Variasi Hidden Neuron } \\
\hline $\begin{array}{l}\text { Hidden } \\
\text { Neuron }\end{array}$ & 6 & 9 & 11 & 13 \\
Learning & 0,00001 & 0,00001 & 0,00001 & 0,00001 \\
Rate & & & & \\
$\begin{array}{l}\text { Epoch } \\
\text { Error }\end{array}$ & 1000 & 1000 & 1000 & 1000 \\
Jumlah & 0,00001 & 0,00001 & 0,00001 & 0,00001 \\
Training & 282 & 282 & 282 & 282 \\
Jumlah & 121 & 121 & 121 & 121 \\
$\begin{array}{l}\text { Testing } \\
\text { Jumlah }\end{array}$ & 38 & 33 & 30 & 44 \\
Benar & & & & \\
Akurasi & $31,41 \%$ & $27,27 \%$ & $24,79 \%$ & $36,36 \%$ \\
\hline
\end{tabular}

Tabel 3. Variasi hidden neuron dengan perbandingan data $80: 20$

\begin{tabular}{lcccc}
\hline \multicolumn{1}{c}{ Variabel } & \multicolumn{4}{c}{ Variasi Hidden Neuron } \\
\hline Hidden & 6 & 9 & 11 & 13 \\
Neuron & & & & \\
Learning Rate & 0,00001 & 0,00001 & 0,00001 & 0,00001 \\
Epoch & 1000 & 1000 & 1000 & 1000 \\
Error & 0,00001 & 0,00001 & 0,00001 & 0,00001 \\
Jumlah & 322 & 322 & 322 & 322 \\
$\begin{array}{l}\text { Training } \\
\text { Jumlah }\end{array}$ & 81 & 81 & 81 & 81 \\
Testing & & & & \\
Jumlah Benar & 21 & 23 & 33 & 26 \\
Akurasi & 25,92 & $28,39 \%$ & $40,74 \%$ & $32,09 \%$ \\
\hline & \multicolumn{4}{c}{} \\
\hline
\end{tabular}

Berdasarkan hasil variasi hidden neuron menggunakan perbandingan data 60:40 pada Tabel 1, 70:30 pada Tabel 2 dan 80:20 pada
Tabel 3, variasi dengan tingkat akurasi tertinggi terjadi pada hidden neuron 11 pada perbandingan data 80:20, dengan tingkat akurasi 40,74\%. Hasil yang didapatkan fluktuatif tiap variasinya, sebab hidden neuron yang digunakan tidak sama. Semakin besar hidden neuron yang digunakan, akurasi yang didapatkan semakin besar. Sesuai dengan teori Heaton (2008) bahwa terdapat beberapa aturan yang dapat digunakan dalam menentukan jumlah neuron pada hidden layer yaitu (1) jumlah hidden layer neuron harus berada diantara ukuran input layer dan output layer; (2) jumlah hidden neuron harus 2/3 dari ukuran input layer ditambah output layer; dan (3) jumlah hidden neuron harus kurang dari dua kali jumlah input layer. Aturan-aturan jumlah hidden neuron tersebut, berpengaruh terhadap pencapaian akurasi.

\section{Variasi Learning Rate}

Pada variasi learning rate, learning rate yang digunakan yaitu 0.01, 0.001, 0.0001, dan 0.00001 . Variasi learning rate ini mempengaruhi tingkat akurasi sistem. Hasil variasi learning rate pada tahap training dan testing dengan menggunakan perbandingan jumlah data 60:40 dapat dilihat pada Tabel 4, sedangkan hasil variasi learning rate dengan perbandingan jumlah data 70:30 dan 80:20 dapat dilihat pada Tabel 5 dan Tabel 6. 
Tabel 4. Variasi learning rate dengan perbandingan data 60:40

\begin{tabular}{|c|c|c|c|c|}
\hline \multirow{2}{*}{$\begin{array}{l}\text { Variabel } \\
\text { Hidden }\end{array}$} & \multicolumn{4}{|c|}{ Variasi Learning Rate } \\
\hline & 13 & 13 & 13 & 13 \\
\hline Neuron & & & & \\
\hline $\begin{array}{l}\text { Learning } \\
\text { Rate }\end{array}$ & 0,01 & 0,001 & 0,0001 & 0,00001 \\
\hline Epoch & 1000 & 1000 & 1000 & 1000 \\
\hline Error & 0,00001 & 0,00001 & 0,00001 & 0,00001 \\
\hline $\begin{array}{l}\text { Jumlah } \\
\text { Training }\end{array}$ & 242 & 242 & 242 & 242 \\
\hline $\begin{array}{l}\text { Jumlah } \\
\text { Testing }\end{array}$ & 161 & 161 & 161 & 161 \\
\hline $\begin{array}{l}\text { Jumlah } \\
\text { Benar }\end{array}$ & 13 & 12 & 46 & 36 \\
\hline Akurasi & $8,07 \%$ & $7,45 \%$ & $28,57 \%$ & $22,36 \%$ \\
\hline
\end{tabular}

Tabel 5. Variasi learning rate dengan perbandingan data 70:30

\begin{tabular}{lcccc}
\hline Variabel & \multicolumn{4}{c}{ Variasi Learning Rate } \\
\hline $\begin{array}{l}\text { Hidden } \\
\text { Neuron }\end{array}$ & 13 & 13 & 13 & 13 \\
$\begin{array}{l}\text { Learning } \\
\text { Rate }\end{array}$ & 0,01 & 0,001 & 0,0001 & 0,00001 \\
$\begin{array}{l}\text { Epoch } \\
\text { Error }\end{array}$ & 1000 & 1000 & 1000 & 1000 \\
Jumlah & 0,00001 & 0,00001 & 0,00001 & 0,00001 \\
$\quad$ Training & 282 & 282 & 282 & 282 \\
$\begin{array}{l}\text { Jumlah } \\
\text { Testing }\end{array}$ & 121 & 121 & 121 & 121 \\
$\begin{array}{l}\text { Jumlah } \\
\text { Benar }\end{array}$ & 10 & 9 & 38 & 44 \\
Akurasi & $8,26 \%$ & $7,43 \%$ & $31,41 \%$ & $36,36 \%$ \\
\hline
\end{tabular}

Tabel 6. Variasi learning rate dengan perbandingan data 80:20

\begin{tabular}{lcccc}
\hline Variabel & \multicolumn{4}{c}{ Variasi Learning Rate } \\
\hline $\begin{array}{l}\text { Hidden } \\
\text { Neuron }\end{array}$ & 11 & 11 & 11 & 11 \\
$\begin{array}{l}\text { Learning } \\
\text { Rate }\end{array}$ & 0,01 & 0,001 & 0,0001 & 0,00001 \\
$\begin{array}{l}\text { Epoch } \\
\text { Error }\end{array}$ & 1000 & 1000 & 1000 & 1000 \\
Jumlah & 320001 & 0,00001 & 0,00001 & 0,00001 \\
$\begin{array}{l}\text { Training } \\
\text { Jumlah }\end{array}$ & 81 & 322 & 322 & 322 \\
$\begin{array}{l}\text { Testing } \\
\text { Jumlah }\end{array}$ & 6 & 6 & 81 & 81 \\
$\begin{array}{l}\text { Benar } \\
\text { Akurasi }\end{array}$ & $7,41 \%$ & $7,41 \%$ & $25,93 \%$ & $40,74 \%$ \\
\hline & & & & \\
\hline
\end{tabular}

Hasil variasi learning rate dengan menggunakan berbagai perbandingan data menunjukkan variasi dengan tingkat akurasi tertinggi terjadi pada learning rate 0.00001 pada perbandingan data 80:20, dengan tingkat akurasi 40,74\%. Diketahui dari tabel bahwa semakin besar learning rate, hasil yang didapatkan tidak stabil. Sebaliknya, jika learning rate yang digunakan semakin kecil akan membutuhkan waktu yang lama dan hasil akurasi yang diperoleh cenderung besar. Sesuai dengan teori Adha (2013) bahwa ketika learning rate kecil pergeseran pada data centroid lebih kecil, sedangkan ketika learning rate terlalu besar pergeseran data centroid akan semakin besar menjauhi optimal yang menyebabkan data tidak stabil.

\section{Analisis Hasil Prediksi Sistem}

Hasil akurasi tertinggi yang diperoleh dari proses training dan testing digunakan untuk memprediksi citra yang diinputkan oleh user. Hasil akurasi sistem ini menunjukkan prediksi jenis dan mutu teh yang benar atau tidak benar dari citra yang diinputkan oleh user. Berdasarkan trial error variabel training hasil training dan testing yang telah dilakukan, diperoleh akurasi tertinggi yaitu 40,74\% yang terdapat pada perbandingan data 80:20 dengan hidden neuron 11 dan learning rate 0.00001 . Akurasi tersebut masih rendah karena pengaruh variabel training atau kesalahan dalam pengambilan gambar yang masih terdapat noise pada saat pengambilan gambar berupa debu pada lensa scanner. Menurut Sutoyo, dkk (2009), rendahnya akurasi dapat disebabkan kesalahan pada pengambilan gambar sehingga proses pengolahan citra tidak optimal, misalnya adanya noise seperti kabut yang menghalangi objek yang sedang di-capture atau lensa kamera kotor. Trial error variabel bebas dengan akurasi tertinggi ditunjukkan pada Tabel 7. 
Tabel 7. Trial error variabel bebas dengan akurasi tertinggi.

\begin{tabular}{lc}
\hline \multicolumn{1}{c}{ Variabel } & Variasi Learning Rate \\
\hline Hidden Neuron & 11 \\
Learning Rate & 0,00001 \\
Epoch & 1000 \\
Error & 0,00001 \\
Jumlah Training & 322 \\
Jumlah Testing & 81 \\
Jumlah Benar & 33 \\
Akurasi & $40,74 \%$ \\
\hline
\end{tabular}

Pada tahap prediksi ini dilakukan pengenalan citra diluar data citra yang digunakan pada saat proses training dan testing. Citra yang digunakan sebanyak 52 citra dengan rincian 4 citra pada masing-masing mutu. Hasil citra yang telah diprediksi dapat dilihat pada Tabel 8. Menurut Kusumadewi (2003), teknik prediksi menggunakan supervised induction, yang memanfaatkan kumpulan pengujian dari record yang terklasifikasi untuk menentukan kelas data baru.

Tabel 8. Hasil citra yang telah diprediksi

\begin{tabular}{lccc}
\hline \multicolumn{1}{c}{ Jenis dan mutu } & $\begin{array}{c}\text { Jumlah } \\
\text { data }\end{array}$ & $\begin{array}{c}\text { Jumlah } \\
\text { salah }\end{array}$ & $\begin{array}{c}\text { Jumlah } \\
\text { benar }\end{array}$ \\
\hline Teh hitam mutu BOP & 2 & 2 & 0 \\
Teh hitam mutu BOPF & 2 & 2 & 0 \\
Teh hitam mutu BP1 & 2 & 2 & 0 \\
Teh hitam mutu PF1 & 2 & 2 & 0 \\
Teh hitam mutu Dust1 & 2 & 0 & 2 \\
Teh hitam mutu BP2 & 2 & 2 & 0 \\
Teh hitam mutu PF2 & 2 & 2 & 0 \\
Teh hitam mutu BM & 2 & 0 & 2 \\
Teh hitam mutu PF3 & 2 & 1 & 1 \\
Teh hijau mutu peko & 2 & 0 & 2 \\
super & & & 2 \\
Teh hijau mutu Jikeng & 2 & 0 & 0 \\
Teh hijau mutu Tualngan & 2 & 2 & 2 \\
Teh putih mutu Silver & 2 & 0 & 11 \\
needle & & & $42,31 \%$ \\
\hline Jumlah & 26 & 15 & \\
\hline Akurasi Prediksi & & &
\end{tabular}

Berdasarkan hasil prediksi yang telah dilakukan, terdapat 11 citra yang benar dan 15 citra salah. Kemudian citra yang benar dilakukan validasi terhadap jumlah data dengan hasil akurasi sebesar 42.31\%. Hasil akurasi dari data prediksi yang diperoleh masih rendah, karena akurasi yang diperoleh sistem juga masih rendah. Menurut Pramudiono (2003), pada proses testing dalam sistem identifikasi, model yang sudah terbentuk diuji dengan sebagian data lainnya untuk mengetahui akurasi dari model tersebut. Jika akurasinya mencukupi, model tersebut dapat dipakai untuk prediksi kelas data yang belum diketahui.

Persentase akurasi diperoleh dengan persamaan 1 (Sarkar dan Leong, 2000).

Akurasi $=\frac{\text { Jumlah prediksi benar }}{\text { Jumlah total } \text { prediksi }} \times 100 \%$

Jumlah prediksi benar adalah jumlah record data uji yang diprediksi kelasnya menggunakan metode klasifikasi dan hasilnya sama dengan kelas sebenarnya. Jumlah total prediksi adalah jumlah keseluruhan record yang diprediksi kelasnya.

Citra benar yaitu citra yang sesuai dengan jenis dan mutu yang telah ditentukan berdasarkan SNI dan standar PPTK Gambung. Hasil prediksi dari 2 gambar pada masingmasing mutu menunjukkan bahwa teh hitam mutu Dust 1 dan mutu BM, teh hijau mutu Peko Super dan Jikeng, dan teh putih mutu silver needle telah sesuai dengan jenis dan mutu teh. Sebaliknya, teh hitam mutu BOP, BOPF, BP1, PF1, BP2, PF2 dan teh hijau mutu Tulangan tidak sesuai dengan jenis dan mutunya.

\section{KESIMPULAN DAN SARAN}

Sistem pengolahan citra digital teh dibuat melalui beberapa tahapan yaitu akuisisi citra, preprocessing, ekstraksi fitur, training dan testing. Tahap akuisisi citra merupakan tahap pengambilan citra melalui scanner yang kemudian di-croping dan resize dengan ukuran $300 \times 300$ piksel. Preprocessing dilakukan untuk 
mengubah citra menjadi citra biner. Tahap ekstraksi fitur membaca nilai-nilai parameter warna RGB dan HSI. Proses training LVQ digunakan untuk mendapatkan arsitektur jaringan terbaik, kemudian proses testing dilakukan untuk menguji arsitektur jaringan yang diperoleh.

Hasil prediksi menggunakan 26 sampel citra teh menunjukkan bahwa terdapat 11 citra yang sesuai dan 15 citra yang tidak sesuai, sehingga tingkat akurasi keberhasilan identifikasi jenis dan mutu teh yang diperoleh sebesar 42,31\%. Hasil pengenalan terbaik pada teh hitam mutu Dust1, BM, PF3, teh hijau mutu Peko super dan Jikeng serta teh putih mutu silver needle.

Saran perbaikan sistem untuk mendapatkan akurasi yang lebih tinggi dapat dilakukan dengan pengembangan metode filtering dengan kombinasi operasi openingclosing serta filter median agar noise tidak terlihat dan menambahkan analisis tekstur pada pengolahan citra digital.

\section{DAFTAR PUSTAKA}

Adha, G. 2013. Pengklasifikasian kualitas minuman anggur menggunakan algoritma learning vector quantization berbasis asosiasi. Skripsi. Universitas Brawijaya. Malang

Adnan, B. Kusbiantoro, dan Suhartini. 2013. Identifikasi varietas berdasarkan warna dan tekstur permukaan beras menggunakan pengolahan citra dan jaringan syaraf tiruan. Jurnal Penelitian Pertanian Tanaman Pangan 32(2):91-96

Adrizal, D.Anggraini, N. Novita, Santosa, dan Andasuryani. 2011. Pendugaan kualitas fisik biji jagung untuk bahan pakan menggunakan jaringan syaraf tiruan berdasarkan data citra digital. Jurnal Peternakan Indonesia Vol. 13 (3)
Azmi, M. 2014. Komparasi metode jaringan syaraf tiruan SOM dan LVQ untuk mengidentifikasi data bunga iris. Jurnal TEKNOIF 2 (1): 65

Dirjen Perkebunan. 2014. Statistik Perkebunan Indonesia 2013-2015: Teh. Direktorat Jenderal Perkebunan. Jakarta

Degang, Y., Guo, C., Hui, W. and Xiaofeng, L. 2007. Learning vector quantization neural network method for network intrusion detection. Journal of Natural Sciences 12 (1): $147-150$

Hartoyo, A. 2007. Teh dan Khasiatnya Bagi Kesehatan. Kanisius. Yogyakarta

Heaton, J. 2008. Programming Neural Networks with Encog 2 In Java. Heaton Research, Inc. St. Louis.

Hendrawan, Y dan Sumardi, HS. 2005. Pengkajian karakteristik mutu buah belimbing manis (Averrhoa carambola L.) dengan teknik pengolahan citra. Jurnal Teknologi Pertanian(6) 2: 131-142

Khan, N., and Mukhtar, H. 2007. Tea polyphenols for health promotion. J. Life Sciences 81: 519-533.

Kusumadewi, S. 2003. Artificial Intelligence: Teknik dan Aplikasinya. Penerbit Graha Ilmu. Yogyakarta

Luthfi, E.T dan Kusrini. 2009. Algoritma Data Mining. Penerbit Andi. Yogyakarta

Mandel, S. A., Avramovich-Tirosh, Y., Reznichenko, L., Zheng, Weinreb, O., and Amit, T. 2005. Multifunctional activities of green tea catechins in neuroprotection. J. Neurosignals 14: 46-60

Rohdiana, D. 2015. Teh: proses, karakteristik dan komponen fungsionalnya. Jurnal Foodreview Indonesia 10 (8): 35

Sarkar dan Leong. 2000. Principles of Data Mining. Cambridge: MIT Press

Somantri, A.S. 2010. Menentukan klasifikasi mutu fisik beras dengan menggunakan teknologi pengolahan citra digital dan 
jaringan syaraf tiruan. Jurnal Badan Standarisasi Nasional 12 (3).

Sutoyo, T., Mulyanto, E., Suhartono, V., Nurhayanti, D. dan Wijanarto. Pengolahan Citra Digital. 2009. Penerbit Andi. Yogyakarta

Yashin, AY; Nemzer, BV; Combet, E and Yashin, YI. 2015. Determination of the chemical composition of tea by chromatographic methods: a review. Journal of Food Research; Vol. 4, No. 3

Warman, K; Harahap, LA, dan Munir, AP. 2015. Identifikasi kematangan buah jeruk dengan teknik jaringan syaraf tiruan. J.Rekayasa Pangan dan Pert., Vol.3 No. 2 